\title{
Conductometric Studies on Terbium Soaps
}

\author{
Kamal Kishore* and S.K Upadhyaya \\ P.G. Department of Chemistry, S.S.L. Jain College, VIDISHA-464001, India
}

Received 30 December 2010; accepted 28 February 2012

\begin{abstract}
Conductivity measurements of solutions of terbium soaps in benzene-methanol show that these soaps behave as weak electrolytes in dilute solutions and Debye-HückelOnsager's equation is not applicable to these soap solutions. The thermodynamic results indicate that the micellization process is favoured over the dissociation process.
\end{abstract}

Keywords: heat of dissociation, critical micellar concentration, micellization, free energy.

\section{Introduction}

Metal soaps have recently become increasing important in technological uses as well as in academic studies. Application of metallic soaps depends largely on their physico-chemical properties such as physical state, thermal stability, chemical reactivity and solubility in polar and non-polar solvents. Metal soap with elements of lanthanide series were synthesised for the first time by Mishra et al. [1]. Mehrotra et al. [2,3] investigated acoustical and thermodynamic properties of lanthanide soaps and concluded that these soaps behave as weak electrolyte in dilute solutions. Upadhyaya et al. [4] studied the thermodynamics of dissociation, micellization and conductance behaviour of alkaline-earth metal soaps. Topallar et al. [5] investigated conductance behaviour of chromium soaps in different solvents. A comparative study on micellization and electrolytic behaviour of dysprosium soaps in methanol was carried out by Shukla et al. [6].

The present manuscript deals with the study of conductance of solutions of terbium palmitate and stearate in a mixture of $60 / 40$ benzene-methanol $(\mathrm{v} / \mathrm{v})$ at different temperatures. The results have been used to find out the nature of these soaps in non-aqueous medium and to determine various thermodynamic parameters.

\footnotetext{
* Corresponding author. E-mail: k_81kishore@yahoo.co.in
} 


\section{Experimental}

Anala R grade palmitic acid, stearic acid, benzene, methanol, acetone and terbium acetate (purity 99.9\%, received from Indian Rare Earth Limited, Kerala) were used for the present investigation. The terbium palmitate and stearate were prepared by direct metathesis of corresponding potassium soaps (palmitate and stearate) by pouring a slight stoichiometric excess of aqueous terbium acetate solution into clear potassium palmitate and stearate dispersion at raised temperature with vigorous stirring. The precipitates were filtered off and washed with hot distilled water and acetone. After initial drying in an air oven $50-60{ }^{\circ} \mathrm{C}$, final drying was carried out under reduced pressure. The purity of soap was checked by the elemental analysis and results were found in agreement with theoretically calculated values. Solutions of terbium soaps were prepared by dissolving a known amount of soap in a mixture of 60/40 benzene-methanol (v/v) and kept for $2 \mathrm{hrs}$ in a thermostat at desired temperature.

The reason for the choice of benzene/methanol $=60 / 40$ can be explained as follows. A terbium soap molecule consists of two parts as a non-polar saturated hydrocarbon chain and a polar carboxylate end. These soaps are very slightly soluble in pure benzene and methanol. Since benzene is a non-polar solvent and methanol is a polar solvent, the hydrocarbon chain has a tendency to dissolve in benzene and the carboxylate end in methanol. The hydrocarbon chain is longer and bulkier than the carboxylate end. However, the hydrocarbon chain requires more benzene to dissolve as 60 volumes and methanol for carboxylate end as 40 volumes. As a result, the terbium soap molecule dissolves better in a mixture of benzene/methanol $=60 / 40$ than in the pure solvents [7]. For this reason, it seems that this solvent mixture was suitable for our experiments.

The conductance of solutions was measured with a "Systronics conductivity Bridge 305" and a dipped type conductivity cell with platinised electrode at 25 , 30,35 and $40{ }^{\circ} \mathrm{C}$. The cell constant (1.0) was measured by using standard solution of potassium chloride. The specific conductance and molar conductance are expressed in mhos $\mathrm{cm}^{-1}$ and $\operatorname{mhos~cm}^{-1}(\mathrm{~g} \mathrm{~mol})^{-1} \mathrm{~L}$, respectively.

Table 1. Specific conductance, $\mathrm{k}$ and molar conductance, $\mu$ of terbium palmitate in a mixture of $60 / 40$ benzene-methanol (v/v).

\begin{tabular}{|c|c|c|c|c|c|c|c|c|}
\hline \multirow{2}{*}{$\mathrm{C} \times 10^{3}$} & \multicolumn{2}{|c|}{$25^{\circ} \mathrm{C}$} & \multicolumn{2}{c|}{$30^{\circ} \mathrm{C}$} & \multicolumn{2}{c|}{$35^{\circ} \mathrm{C}$} & \multicolumn{2}{c|}{$40^{\circ} \mathrm{C}$} \\
\cline { 2 - 9 } & $\mathrm{k} \mathrm{x} 10^{6}$ & $\mu$ & $\mathrm{k} \mathrm{x} 10^{6}$ & $\mu$ & $\mathrm{k} \mathrm{\times} 10^{6}$ & $\mu$ & $\mathrm{k} \mathrm{\times} 10^{6}$ & $\mu$ \\
\hline 1.9 & 6.50 & 3.421 & 6.65 & 3.500 & 6.80 & 3.579 & 7.05 & 3.170 \\
\hline 2.1 & 6.81 & 3.243 & 7.00 & 3.333 & 7.26 & 3.457 & 7.50 & 3.571 \\
\hline 2.3 & 7.14 & 3.104 & 7.35 & 3.196 & 7.60 & 3.304 & 7.82 & 3.400 \\
\hline 2.5 & 7.50 & 3.000 & 7.76 & 3.104 & 8.00 & 3.200 & 8.24 & 3.296 \\
\hline 2.8 & 7.76 & 2.771 & 8.10 & 2.893 & 8.52 & 3.043 & 8.75 & 3.125 \\
\hline 3.1 & 8.00 & 2.581 & 8.32 & 2.684 & 8.71 & 2.810 & 9.05 & 2.919 \\
\hline 3.6 & 8.35 & 2.319 & 8.71 & 2.419 & 9.00 & 2.500 & 9.35 & 2.597 \\
\hline 4.2 & 8.85 & 2.107 & 9.10 & 2.167 & 9.45 & 2.250 & 9.74 & 2.319 \\
\hline 5.0 & 9.50 & 1.900 & 9.70 & 1.940 & 10.00 & 2.000 & 10.25 & 2.050 \\
\hline
\end{tabular}




\section{Results and discussion}

The variation of specific and molar conductance with concentration and temperature has been mentioned in Tables 1 and 2 for terbium soaps. Specific conductance, $\mathrm{k}$, of the solutions of terbium palmitate and stearate in a mixture of $60 / 40$ benzene-methanol mixture (v/v) increases with an increase in soap concentration, $\mathrm{C}$, temperature and decrease in chain-length of the soaps (Fig. 1). The increase in the specific conductance with soap concentration may have been due to partial dissociation of these soaps in mixed organic solvent, in dilute solutions. However, an increase in specific conductance at higher soap concentration is probably due to formation of ionic micelles.

Table 2. Specific conductance, $\mathrm{k}$ and molar conductance, $\mu$ of terbium stearate in a mixture of $60 / 40$ benzene-methanol (v/v).

\begin{tabular}{|c|c|c|c|c|c|c|c|c|}
\hline \multirow{2}{*}{$\mathrm{C} \times 10^{3}$} & \multicolumn{2}{|c|}{$25^{\circ} \mathrm{C}$} & \multicolumn{2}{c|}{$30^{\circ} \mathrm{C}$} & \multicolumn{2}{c|}{$35^{\circ} \mathrm{C}$} & \multicolumn{2}{c|}{$40^{\circ} \mathrm{C}$} \\
\cline { 2 - 9 } & $\mathrm{k} \times 10^{6}$ & $\mu$ & $\mathrm{k} \times 10^{6}$ & $\mu$ & $\mathrm{k} \mathrm{\times} 10^{6}$ & $\mu$ & $\mathrm{k} \times 10^{6}$ & $\mu$ \\
\hline 1.9 & 6.25 & 3.289 & 6.50 & 3.421 & 6.70 & 3.526 & 6.95 & 3.658 \\
\hline 2.1 & 6.60 & 3.143 & 6.85 & 3.262 & 7.05 & 3.357 & 7.26 & 3.457 \\
\hline 2.3 & 7.00 & 3.043 & 7.21 & 3.135 & 7.41 & 3.222 & 7.60 & 3.304 \\
\hline 2.5 & 7.32 & 2.928 & 7.50 & 3.000 & 7.75 & 3.100 & 8.00 & 3.200 \\
\hline 2.8 & 7.55 & 2.696 & 7.82 & 2.793 & 8.26 & 2.950 & 8.50 & 3.036 \\
\hline 3.1 & 7.76 & 2.503 & 8.00 & 2.581 & 8.42 & 2.716 & 8.76 & 2.826 \\
\hline 3.6 & 8.00 & 2.222 & 8.24 & 2.289 & 8.70 & 2.417 & 9.00 & 2.500 \\
\hline 4.2 & 8.40 & 2.000 & 8.65 & 2.059 & 9.00 & 2.143 & 9.32 & 2.219 \\
\hline 5.0 & 8.90 & 1.780 & 9.11 & 1.822 & 9.50 & 1.900 & 9.71 & 1.942 \\
\hline
\end{tabular}

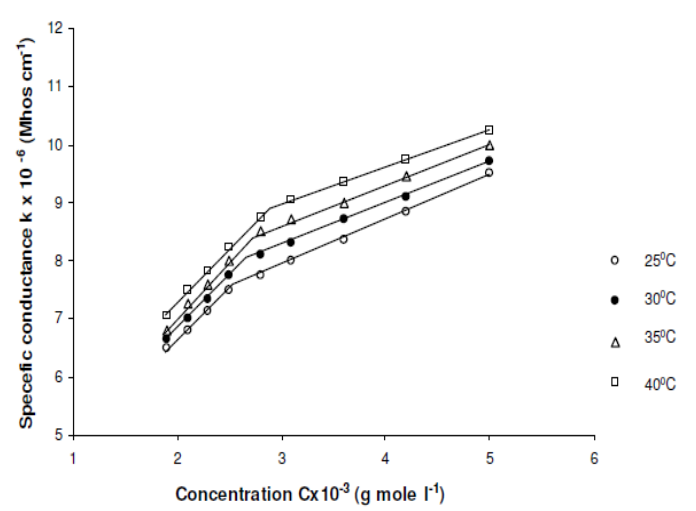

Figure 1. Specific conductance, k vs. concentration, C, of terbium palmitate.

The decrease in specific conductance with increasing the number of carbon atoms in the fatty acid chain of the soap molecules may have been due to the higher molecular weight and decreasing mobility of anions. The plots of specific conductance, k, vs. soap concentration, C, (Fig. 1) are characterized by a break, corresponding to $\mathrm{CMC}$ (Table 3), indicating that micelle formation takes place at a definite soap concentration.

Molar conductance, $\mu$, of terbium soaps (palmitate and stearate) solutions in 60/40 benzene-methanol mixture (v/v) decreases with increasing concentration and chain-length of the soaps. The critical micellar concentration, CMC, cannot be, however obtained from the plots of molar conductance vs. square root of soap 
concentration, which are concave upwards with increasing slopes indicating that soaps behave as weak electrolyte in dilute solutions (Fig. 2). The decrease in molar conductance is attributed to the combined effects of ionic atmosphere, solvation of ions and decrease in mobility and ionization with the formation of micelles.

Table 3. Critical micellar concentration, $\mathrm{CMC}\left(\mathrm{g} \mathrm{mol} \mathrm{L}^{-1}\right)$ of terbium palmitate and stearate in a mixture of 60/40 benzene-methanol (v/v) at various temperatures.

\begin{tabular}{|c|c|c|c|c|}
\hline \multirow{2}{*}{ Name of the soap } & \multicolumn{4}{|c|}{$\mathrm{CMC} \times 10^{3}$} \\
\cline { 2 - 5 } & $25^{\circ} \mathrm{C}$ & $30{ }^{\circ} \mathrm{C}$ & $35^{\circ} \mathrm{C}$ & $40{ }^{\circ} \mathrm{C}$ \\
\hline Terbium palmitate & 2.56 & 2.66 & 2.76 & 2.88 \\
\hline Terbium stearate & 2.52 & 2.64 & 2.74 & 2.87 \\
\hline
\end{tabular}

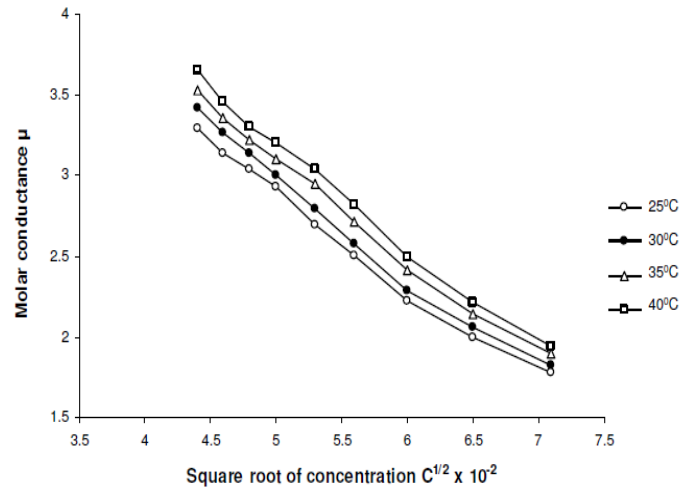

Figure 2. Molar conductance, $\mu$ vs. square root of concentration, $C^{1 / 2}$, of terbium stearate.

The Debye-Hückel-Onsager's equation [8] is not applicable to these soap solutions. Molar conductance results indicate that terbium palmitate and stearate behave as weak electrolytes in dilute solutions; the following expression [9] for their dissociation can be derived.

$$
\mu^{2} C^{2}=\frac{K_{D} \mu_{0}^{3}}{4 \mu}-\frac{K_{D} \mu_{0}^{2}}{4}
$$

The dissociation constant, $\mathrm{K}_{\mathrm{D}}$, and limiting molar conductance, $\mu_{0}$, (Table 4) have been obtained from the slope, $\frac{\mathrm{K}_{\mathrm{D}} \mu_{0}^{3}}{4}$ and the intercept, $-\frac{\mathrm{K}_{\mathrm{D}} \mu_{0}^{2}}{4}$ of the linear plots of $\mu^{2} \mathrm{C}^{2}$ vs. $1 / \mu$ for dilute soap solutions. It is observed that an increase in temperature brings about an increase in the limiting conductance at infinite dilution, $\mu_{0}$, and decrease in their dissociation constant, $K_{D}$ (Table 4 ).

The decrease in the value of the dissociation constant with increasing temperature indicates the exothermic nature of the dissociation of these terbium soaps in a mixture of $60 / 40$ benzene-methanol. The degree of dissociation, $\alpha$, at various soap concentrations can be measured by using it to be equal to the conductance ratio, $\mu / \mu_{0}$. 
Table 4. Molar conductance at infinite dilution, $\mu_{0}$, and dissociation constant, $\mathrm{K}_{\mathrm{D}}$, of terbium palmitate and stearate in a mixture of 60/40 benzene-methanol (v/v) at various temperatures.

\begin{tabular}{|c|c|c|c|c|c|c|c|c|}
\hline \multirow{2}{*}{$\begin{array}{l}\text { Name of } \\
\text { the soap }\end{array}$} & \multicolumn{2}{|c|}{$25^{\circ} \mathrm{C}$} & \multicolumn{2}{|c|}{$30^{\circ} \mathrm{C}$} & \multicolumn{2}{|c|}{$35^{\circ} \mathrm{C}$} & \multicolumn{2}{|c|}{$40^{\circ} \mathrm{C}$} \\
\cline { 2 - 9 } & $\mu_{0}$ & $\mathrm{~K}_{\mathrm{D}} \times 10^{5}$ & $\mu_{0}$ & $\mathrm{~K}_{\mathrm{D}} \times 10^{5}$ & $\mu_{0}$ & $\mathrm{~K}_{\mathrm{D}} \times 10^{5}$ & $\mu_{0}$ & $\mathrm{~K}_{\mathrm{D}} \times 10^{5}$ \\
\hline $\begin{array}{c}\text { Terbium } \\
\text { palmitate }\end{array}$ & 4.51 & 1.99 & 4.55 & 1.84 & 4.63 & 1.72 & 4.79 & 1.58 \\
\hline $\begin{array}{c}\text { Terbium } \\
\text { stearate }\end{array}$ & 4.46 & 1.97 & 4.51 & 1.81 & 4.62 & 1.67 & 4.75 & 1.53 \\
\hline
\end{tabular}

The heat of dissociation, $\Delta \mathrm{H}_{\mathrm{D}}$, for terbium palmitate and stearate is determined by using the following equation:

$$
\log \mathrm{K}_{\mathrm{D}}=-\frac{\Delta \mathrm{H}_{\mathrm{D}}}{2.303 \mathrm{RT}}+\mathrm{c}
$$

The values of heat of dissociation, $\Delta \mathrm{H}_{\mathrm{D}}$, were obtained from the slope of the linear plots of $\log \mathrm{K}_{\mathrm{D}}$ vs. 1/T (Fig. 3) and mentioned in Table 5. Since the values of heat of dissociation, $\Delta \mathrm{H}_{\mathrm{D}}$, are negative, indicates that the dissociation process for terbium soaps (palmitate and stearate) is exothermic in nature.

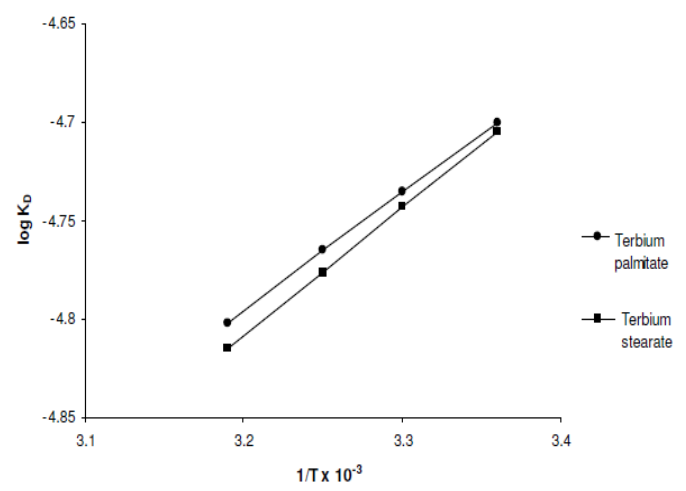

Figure 3. $\log K_{D}$ versus $1 / T$ for terbium palmitate and stearate.

Table 5. Heat of dissociation, $\Delta \mathrm{H}_{\mathrm{D}}$ and heat of micellization, $\Delta \mathrm{H}_{\mathrm{M}}$ of terbium palmitate and stearate in a mixture of $60 / 40$ benzene-methanol $(\mathrm{v} / \mathrm{v})$ at various temperatures.

\begin{tabular}{|l|c|c|}
\hline Name of the soap & $-\Delta \mathrm{H}_{\mathrm{D}}\left(\mathrm{KJ} \mathrm{mol}^{-1}\right)$ & $\Delta \mathrm{H}_{\mathrm{M}}\left(\mathrm{KJ} \mathrm{mol}^{-1}\right)$ \\
\hline Terbium palmitate & 12.50 & 12.19 \\
\hline Terbium stearate & 13.17 & 12.75 \\
\hline
\end{tabular}

The values of change in free energy, $\Delta \mathrm{G}_{\mathrm{D}}$, and standard entropy change, $\mathrm{T} \Delta \mathrm{S}_{\mathrm{D}}$, for the dissociation process are calculated by using the relations:

$$
\begin{aligned}
\Delta \mathrm{G}_{\mathrm{D}} & =-\mathrm{RT} \ln \mathrm{K}_{\mathrm{D}} \\
\mathrm{T} \Delta \mathrm{S}_{\mathrm{D}} & =\Delta \mathrm{H}_{\mathrm{D}}-\Delta \mathrm{G}
\end{aligned}
$$

The calculated values of $\Delta \mathrm{G}_{\mathrm{D}}$ and $\mathrm{T} \Delta \mathrm{S}_{\mathrm{D}}$ are recorded in Table 6. 
Table 6. Thermodynamic parameters of the dissociation of terbium palmitate and stearate in a mixture of 60/40 benzene-methanol (v/v) at various temperatures.

\begin{tabular}{|c|c|c|c|c|}
\hline $\begin{array}{c}\text { Temperature } \\
\left({ }^{\circ} \mathrm{C}\right)\end{array}$ & \multicolumn{2}{|c|}{ Terbium palmitate } & \multicolumn{2}{c|}{ Terbium stearate } \\
\cline { 2 - 5 } & $\Delta \mathrm{G}_{\mathrm{D}}$ & $-\mathrm{T} \Delta \mathrm{S}_{\mathrm{D}}$ & $\Delta \mathrm{G}_{\mathrm{D}}$ & $-\mathrm{T} \Delta \mathrm{S}_{\mathrm{D}}$ \\
\hline $25^{\circ} \mathrm{C}$ & 26.81 & 39.31 & 26.84 & 40.01 \\
\hline $30^{\circ} \mathrm{C}$ & 27.46 & 39.96 & 27.51 & 40.68 \\
\hline $35^{\circ} \mathrm{C}$ & 28.09 & 40.59 & 28.16 & 41.33 \\
\hline $40^{\circ} \mathrm{C}$ & 28.77 & 41.27 & 28.84 & 42.01 \\
\hline
\end{tabular}

In case of micellization, i.e., aggregation process, when counter-ions are bound to a micelle, the standard free energy change of micellization, $\Delta \mathrm{G}_{\mathrm{M}}$, for the phase separation model [10-12] is given by

$$
\Delta \mathrm{G}_{\mathrm{M}}=2 \mathrm{RT} \ln \mathrm{X}_{\mathrm{CMC}}
$$

where $\mathrm{X}_{\mathrm{CMC}}$ is the $\mathrm{CMC}$ expressed as a mole fraction and is defined as,

$$
\mathrm{X}_{\mathrm{CMC}}=\mathrm{n}_{\mathrm{S}} / \mathrm{n}_{\mathrm{S}}+\mathrm{n}_{0}=\mathrm{n}_{\mathrm{S}} / \mathrm{n}_{0}
$$

since the numbers of moles of free soap, $\mathrm{n}_{\mathrm{s}}$, are small as compared to the number of moles of solvent, $\mathrm{n}_{0}$.

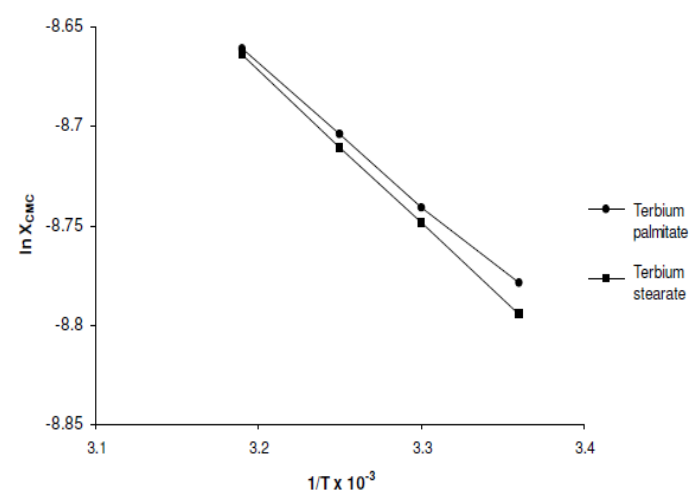

Figure 4. $\ln \mathrm{X}_{\mathrm{CMC}}$ versus $1 / \mathrm{T}$ for terbium palmitate and stearate.

The standard enthalpy change of micellization, $\Delta \mathrm{H}_{\mathrm{M}}$, for phase separation model is evaluated as follows:

$$
\ln \mathrm{X}_{\mathrm{CMC}}=\frac{\Delta \mathrm{H}_{\mathrm{M}}}{2 \mathrm{RT}}+\mathrm{c}
$$

The values of $\Delta \mathrm{H}_{\mathrm{M}}$ have been determined from the slope of linear plots of $\mathrm{ln}$ $\mathrm{X}_{\mathrm{CMC}}$ vs. 1/T (Fig. 4) and mentioned in Table 5. The positive enthalpy for micellization, $\Delta \mathrm{H}_{\mathrm{M}}$, indicates that the association of terbium palmitate and stearate in $60 / 40$ benzene-methanol $(\mathrm{v} / \mathrm{v})$ is endothermic.

The standard entropy change for micellization is calculated as,

$$
\mathrm{T} \Delta \mathrm{S}_{\mathrm{M}}=\Delta \mathrm{H}_{\mathrm{M}}-\Delta \mathrm{G}_{\mathrm{M}}
$$


Table 7. Thermodynamic parameters of the association of terbium palmitate and stearate in a mixture of $60 / 40$ benzene-methanol $(\mathrm{v} / \mathrm{v})$ at various temperatures.

\begin{tabular}{|c|c|c|c|c|}
\hline $\begin{array}{c}\text { Temperature } \\
\left({ }^{\circ} \mathrm{C}\right)\end{array}$ & \multicolumn{2}{|c|}{ Terbium palmitate } & \multicolumn{2}{c|}{ Terbium stearate } \\
\cline { 2 - 5 } & $-\Delta \mathrm{G}_{\mathrm{M}}$ & $\mathrm{T} \Delta \mathrm{S}_{\mathrm{M}}$ & $-\Delta \mathrm{G}_{\mathrm{M}}$ & $\mathrm{T} \Delta \mathrm{S}_{\mathrm{M}}$ \\
\hline $25{ }^{\circ} \mathrm{C}$ & 43.50 & 55.69 & 43.58 & 56.33 \\
\hline $30^{\circ} \mathrm{C}$ & 44.04 & 56.23 & 44.08 & 56.83 \\
\hline $35^{\circ} \mathrm{C}$ & 44.57 & 56.76 & 44.61 & 57.36 \\
\hline $40^{\circ} \mathrm{C}$ & 45.07 & 57.26 & 45.09 & 57.84 \\
\hline
\end{tabular}

The micellization of the soaps (Table 5 and 7) in a mixture of 60/40 benzenemethanol $(\mathrm{v} / \mathrm{v})$ is consistent with $\Delta \mathrm{H}_{\mathrm{M}}>0, \Delta \mathrm{G}_{\mathrm{M}}<0, \mathrm{~T} \Delta \mathrm{S}_{\mathrm{M}}>0$. However, dissociation of these soaps is consistent with $\Delta \mathrm{H}_{\mathrm{D}}<0, \Delta \mathrm{G}_{\mathrm{D}}>0, \mathrm{~T} \Delta \mathrm{S}_{\mathrm{D}}<0$. The results are in consistent with other data [13-14].

The negative value of free energy of micellization, $\Delta \mathrm{G}_{\mathrm{M}}$, positive value of $\Delta \mathrm{S}_{\mathrm{M}}$ for micellization and positive value of $\Delta \mathrm{G}_{\mathrm{D}}$ and negative value of $\Delta \mathrm{S}_{\mathrm{D}}$ for the dissociation indicate that micellization process is favoured over the dissociation process. It may, therefore, be inferred that in a mixture of 60/40 benzenemethanol (v/v) terbium palmitate and stearate behave as weak electrolytes. The values of the critical micellar concentration increase with increasing temperature and the micellization process is predominating over dissociation process.

\section{References}

1. S.N. Mishra, T.N. Mishra and R.C. Mehrotra, J. Inorg. Nucl. Chem. 25 (1963) 195.

2. K.N. Mehrotra, A.S. Gahlaut and M. Sharma, J. Colloid and Interface Sci. 120 (1987) 110.

3. K.N. Mehrotra and S.K. Upadhyaya, J. Am. Oil Chemists Soc. 67 (1990) 464.

4. $\quad$ S.K. Upadhyaya and C. Singh, Asian J. Chem. 18 (2006) 129.

5. H. Topallar and Y. Bayrak, Tr. J. Chem. 22 (1998) 167.

6. R.K. Shukla, S.K. Upadhyay, M. Shukla, M. Gupta and G. Sharma, J. Ind. Chem. Soc. 86 (2009) 171.

7. $\quad$ K.N. Mehrotra, S.K. Upadhyaya, Colloid Polym. Sci. 267 (1989) 741.

8. I.N. Levine, Physical Chemistry, Fourth Edition, McGraw Hill Inc., p.485 (1995).

9. C.A. Kraus and W.C. Bray, J. Am. Chem. Soc. 35 (1913) 1315.

10. B.W. Barry and G.F. Russel, J. Colloid Interface Sci. 40 (1972) 174.

11. D.C. Robins and I.L. Thomas, J. Colloid Interface Sci. 26 (1968) 407.

12. D. Attwood and A.T. Florence, Surfactant Systems, London-New York, p.100 (1983).

13. K. Kishore and S.K. Upadhyaya, Tenside Surfactants Detergents, 47 (2010) 184-189.

14. K. Kishore and S.K. Upadhyaya, Portugaliae Electrochimica Acta, 28 (2010) 213-219. 